\title{
Antenatal Diagnosis and Management of Nuchal Cystic Hygroma
}

\author{
Jeanne Hortence Fouedjio, Florent Ymele Fouelifack
}

\begin{abstract}
Ultrasonographic evaluation, as a routine component of antenatal care, has significantly contributed to in utero assessment of pregnancy status. The detection of fetal abnormalities by ultrasound, however, has raised clinical questions and created parental dilemmas concerning the outcomes of such pregnancies. A relatively frequent anomaly observed on routine ultrasonographic examination is the posterior nuchal cystic hygroma. Most cases of cystic hygromas are associated with chromosomal abnormalities. Only 2 to $3 \%$ survival rate is reported when fetal cystic hygromas are diagnosed in utero. This information should be helpful when counseling patients whose pregnancies involve fetuses with this anomaly. We report a case of nuchal cystic hygroma diagnosed in the second trimester of pregnancy with the aid of an ultrasonographic morphological analysis. Parents requested termination of pregnancy.
\end{abstract}

Keywords: Nuchal cystic hygroma, Chromosomal abnormalities, Patients counseling.

How to cite this article: Fouedjio JH, Fouelifack FY. Antenatal Diagnosis and Management of Nuchal Cystic Hygroma. Donald School J Ultrasound Obstet Gynecol 2012;6(1):109-111.

Source of support: Nil

Conflict of interest: None declared

\section{CASE REPORT}

A 20-year-old woman primigravida was admitted in our service for late threatening abortion at 16 weeks of an unwanted pregnancy. The history revealed that 2 days before she had vaginal spotting associated with slight pelvic pain.

The systemic review revealed lower abdominal pains, leukorrhea, nausea, vomiting, dizziness.

Despite the fact that the pregnancy was not desired, there were no attempts to terminate it.

Also, neither had the patient been sick or had taken any medications early in the pregnancy. An ultrasound examination performed at 10 weeks of gestation was normal.

On physical examination, the general habitus was good. The patient was conscious. Her conjunctivae were well colored with white sclera.

The blood pressure was 130/80 mm Hg. The heart rate was 80 beats per minute, the respiratory rate was 21 cycles per minute. The cardiopulmonary examination was normal. The lower abdomen was slightly distended.

On vaginal examination, the cervix was posterior, soft, long and closed. On bimanual examination, uterus was increased in size approximating the size of a 15 weeks

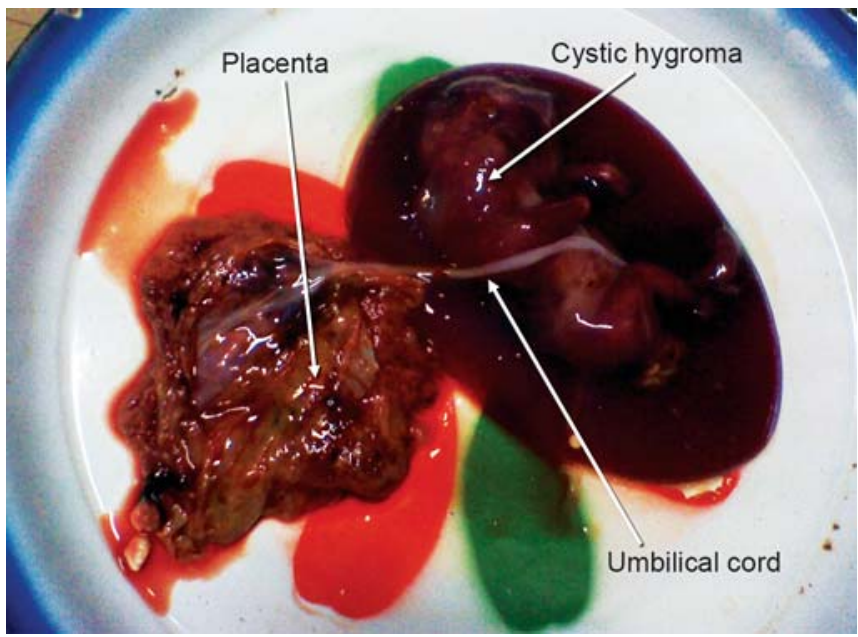

Fig. 1: Fetus at 14 weeks 6 days with nuchal cystic hygroma

gestation. The ultrasound examination reported a singleton pregnancy at 14 weeks and 6 days, a live fetus with cervical hygroma and bilateral pleural effusion. The $\beta$-HCG level was elevated at $101.085 \mathrm{UI} / \mathrm{ml}$ (normal $\leq 30 \mathrm{UI} / \mathrm{ml}$ ) and $\alpha$-fetoprotein level was elevated at 189,72 UI/ml (normal = $20 \mathrm{UI} / \mathrm{ml}$ ). We did not conduct any genetic tests because of nonavailability. Genetic tests are not helpful for the diagnosis but help to determine the chromosomal abnormalities associated with cystic hygroma (Fig. 1).

After counseling, the family requested termination of pregnancy which was done.

\section{DISCUSSION}

Nuchal cystic hygromas are characterized by single or multiple congenital cysts of the lymphatic system, most commonly found within the soft tissues of the neck. The frequency is one in 875 spontaneous abortions. ${ }^{1,2}$

Nuchal cystic hygromas are the clinical consequence of a delay in development or absence of the communications that normally develop between the jugular lymph sacs and the internal jugular veins at approximately 40 days gestation. The obstructed jugular lymph sacs dilate along the paths of least resistance into the posterior and lateral cervical areas. Late communication of the sacs with the internal jugular vein may be manifest by redundancy of the posterior nuchal skin, neck webbing and elevation and anterior rotation of the ears. Complete lymphatic obstruction may be associated with nonimmune fetal hydrops, which is frequently fatal. ${ }^{3}$ 
About $78 \%$ of patients with cystic hygroma are chromosomally abnormal; 58\% have a karyotype associated with Turner syndrome phenotype; while autosomal trisomies and various structural abnormalities made up the remaining $20 \%{ }^{4,5}$ The most common associated structural malformations are cardiac abnormalities. ${ }^{6}$ Even among the $22 \%$ of fetuses with normal chromosomes, various physical anomalies are present. ${ }^{4,5}$

Other syndromes associated with cystic hygromas are Noonan syndrome (autosomal dominant), Pena-Shokeir syndrome, Down syndrome, Robert's syndrome (autosomal recessive), and Multiple pterigium syndrome (autosomal recessive, $\mathrm{X}$-linked).

\section{Ultrasonographic Findings ${ }^{7}$}

1. The fetus present with large bilateral cystic areas termed cystic hygromas develop within the skin in the posterolateral aspect of the neck. They may grow so large that they lie adjacent to each other. It then appears that there is a cystic mass arising from the back of the neck with 1 to 3 septa in the center. The skin thickening is most pronounced in the upper torso and cranium. Hydrops occurs in more severe cases with large pleural effusions, pericardial effusions and ascites.

2. Amniotic fluid is often reduced.

3. Placenta is normal or thickened with hydrops.

Differential diagnosis is encephalocele or meningocele (the mass is posterior and is a single mass. It is associated with a cranial defect) and unfused amniotic membrane.

\section{Biochemical Findings}

Fetus with $45 \mathrm{X}$ karyotype and cystic hygroma are associated with an elevated amniotic alpha-fetoprotein (AFP) level (greater than $80 \mathrm{microgram} / \mathrm{ml}) .{ }^{8}$ AFP evaluation of both maternal serum and amniotic fluid is not helpful in determining prognosis of these fetuses. ${ }^{5}$

In our case, the AFP level was elevated, but we did not perform genetics tests.

\section{Options for Management of the Pregnancy}

Monitoring: Serial sonographic examinations every 3 to 4 weeks should be performed for those conditions likely to progress to fetal hydrops. Assessment for signs of polyhydramnios and preeclampsia should be done in cases with hydrops. The course of pregnancy may become complicated. Both polyhydramnios and preeclampsia may complicate conditions that are associated with fetal hydrops. Cystic hygroma with hydrops is almost always a lethal combination, with death within a short time period. Fetal hydrops is present in $66 \%$ of cases. Cystic hygroma without hydrops usually regress completely. Twenty-two percent result in fetal death in utero prior to any intervention. ${ }^{4,5}$

Pregnancy termination issues: Unless a precise diagnosis has been established prenatally, the method of termination should be nondestructive and examinations by both a fetal pathologist and a dysmorphologist should be perfomed. Seventy-three percent of cases are terminated at the parents' request. ${ }^{5}$

Fetal intervention: In utero drainage procedures have no role in management. Spontaneous resolution is common. Progression to fetal hydrops suggests a generalized severe condition that will not respond to drainage of one body cavity.

Delivery: Except in the case of markedly excessive size, the presence of a cystic hygroma should not necessitate a cesarean section.

\section{CONCLUSION}

Fetuses with cystic hygroma are at high risk for adverse outcome. The financial and emotional burden associated with managing a child with cystic hygroma makes its early antenatal diagnosis and proper management a prime objective in obstetric care. Ultrasonographic investigations carried out early in pregnancy and performed by an experienced ultrasonographer will make possible the diagnosis. The most solicited treatment option being termination of pregnancy, the earlier the diagnosis and treatment, the better the maternal outcome.

\section{REFERENCES}

1. Azar GB, Snijders RJM, Gosden C, Nicolaides KH. Fetal nuchal cystic hygroma: Associated malformations and chromosomal defects. Fetal Diagn Ther 1991;6:46-57.

2. Bronshtein M, Bar-Hava I, Blumenfeld I. The difference between septated and nonseptated nuchal cystic hygroma in the early second trimester. Obstet Gynecol 1993;81:683-87.

3. Chervenak FA, Isaacson G, Blakemore KJ. Fetal cystic hygroma. Cause and natural history. N Engl J Med 1983;309:822-25.

4. Abramowicz JS, Warsof SL, Doyle DL, Smith D, Levy DL. Congenital cystic hygroma of the neck diagnosed prenatally: Outcome with normal and abnormal karyotype. Prenat Diagn May 1989;9(5):321-27.

5. Cohen MM, Schwartz S, Schwartz MF, Blitzer MG, Raffel LJ, Mullins-Keene CL, et al. Antenatal detection of cystic hygroma. Obstet Gynecol Surv June 1989;44(6):481-90. 
6. Gedikbasi A, Gul A, Sargin A, Ceylan Y. Cystic hygroma and lymphangioma: Associated findings, perinatal outcome and prognostic factors in live-born infants. Arch Gynecol Obstet Nov 2007;276(5):491-98.

7. Zimmer EZ, Drugan A, Ofir C. Ultrasound imaging of fetal neck anomalies: Implications for the risk of aneuploidy and structural anomalies. Prenat Diagn 1997;17:1055-58.

8. Rosendorff J, Mayo JR, Reichman P, Blitzer MG, Raffel LJ, Mullins-Keene CL. Elevated alpha-fetoprotein levels in the 45,X (Turner syndrome) fetus with cystic hygroma. Case reports. S Afr Med J 16 Oct 1982;62(17):621-24.

\section{ABOUT THE AUTHORS}

Jeanne Hortence Fouedjio (Corresponding Author)

Specialist, Department of Obstetrics and Gynecology, Faculty of Medicine and Biomedical Sciences, University of Yaounde I, PO Box-1364, Yaounde, Cameroon, e-mail: fouedjiojeanne@yahoo.fr

\section{Florent Ymele Fouelifack}

Specialist, Department of Obstetrics and Gynecology, Central Hospital Yaounde, Cameroon 